\title{
Synthesis of Novel Palladacycles Inhibitors of the Cathepsin B Activity and Antitumoral Agents
}

\author{
Abdel-Sattar S Hamad Elgazwy ${ }^{1 *}$, Mohamed R Shehata ${ }^{2}$, Myssoune Y Zaki ${ }^{3}$, Dalia H S Solima ${ }^{4}$ and Marwa M Elbakkry ${ }^{1,2}$ \\ ${ }^{1}$ Department of Chemistry, Faculty of Science, Ain Shams University, Abbassia 11566, Cairo, Egypt \\ ${ }^{2}$ Department of Chemistry, Faculty of Science, Cairo University, Giza, Egypt \\ ${ }^{3}$ National Organization for Drug Control and Research, Cairo, Egypt \\ ${ }^{4}$ Department of Pharmaceutical Chemistry, Faculty of Pharmacy (Girls' Branch), Al Azahar University, Nasser city, Cairo, Egypt
}

\begin{abstract}
The reaction of 2-bromo-3,4,5-trimethoxybenzaldehyde 1 with $\mathrm{Pd}(\mathrm{dba})_{2}$; dba=dibenzylideneacetone) in the presence of a stoichiometric amount of nitrogen donor ligands, such as $N, N, N^{\prime}, N^{\prime}$-tetramethyl-ethane-1,2-diamine (TMEDA), 2,2'-bipyridine (bpy) 4,4'-dimethyl-2,2'-bipyridine (dmbpy) and an 1,10-phenanthroline (Phen), should be added to with equimolar ratio in degassed acetone under nitrogen to give mononuclear $\sigma$-aryl palladium (II) complexes cis-[2$\left.\mathrm{Pd}\left\{\mathrm{C}_{6} \mathrm{H}(\mathrm{CHO})-6-(\mathrm{OMe})_{3}-3,4,5\right\} \mathrm{BrL}_{2}\right]$ 3a-d, where $\mathrm{L}_{2}=\operatorname{TMEDA}(3 a) ; \mathrm{L}_{2}=$ bpy (3b); $\mathrm{L}_{2}=$ dmbpy (3c); $\mathrm{L}_{2}=$ Phen (3d) in good yields $48-65 \%$. The reaction of the synthesized five-membered $C, N$-palladacycle cis-[2- $\mathrm{Pd}\left\{\mathrm{C}_{6} \mathrm{H}(\mathrm{CHO})-6-(\mathrm{OMe})_{3}-3,4,5\right\}$ $\left.\mathrm{BrL}_{2}\right]$ 3a-d, where $\mathrm{L}_{2}=$ TMEDA (3a); $\mathrm{L}=$ bpy (3b); $\mathrm{L}_{2}=\mathrm{dmbpy}(3 \mathrm{c}) ; \mathrm{L}_{2}=$ Phen (3d), with an1-naphthylisocyanates $\left(\mathrm{C}_{10} \mathrm{H}_{7}-\right.$ $\mathrm{NCO}$ ) and an 1-naphthylisothiocyanates $\left(\mathrm{C}_{10} \mathrm{H}_{7}-\mathrm{NCS}\right)$, leads to the formation of novel palladacycle 4a-d and 5a-d, which was characterized in solution by ${ }^{1} \mathrm{H}$ NMR spectroscopy. The solid products were characterized by satisfactory elemental analysis and spectra studies. All the resulting complexes $3 a-d, 4 a-d$ and $5 a-d$ were tested in vitro against a number of cell lines. For example, it inhibited K562 leukaemia cells with an IC $\mathrm{C}_{50}$ value in the range of (3.00 -4.3) $\mu \mathrm{M}(1$ $\mathrm{h}$ exposure) and displayed cathepsin B inhibitory action with an $\mathrm{IC}_{50}$ value in the range of $(0.045-0.055 \mu \mathrm{M})$.
\end{abstract}

Keywords: Palladium complexes; 1-naphthyl isocyanate; Isothiocyanate; Palladacycles

\section{Introduction}

Palladium (II) complexes show a discrete antitumor activity in vitro compared to the platinum-based drugs because of their extremely high liability in biologic fluids [1]. We have a long-standing interest in palladium chemistry, especially palladacycles, which are molecules containing a $\mathrm{C}-\mathrm{Pd}$ bond stabilized intra-molecularly by a dative bond (e.g. N-, S-,O-, P-, Se- donor) [2-4]. Palladacycles are described in the literature as promising antitumor agents [5-16], but have yet to make sufficient progress to clinical trials for evaluation as drugs [17].

Nevertheless, a recent breakthrough from Caires et al. [18] has shown that a number of $\mathrm{C}, \mathrm{N}$-palladacycles were non-cytotoxic anticancer activity, and have notable cathepsin B inhibitory activity with the potential to treat metastatic cancer $[19,20]$. However, palladacycles are more stable, and, most important, less toxic, suggesting they could have a more specific antitumor activity in vivo [1,21-23]. The promising results derived from palladacycles have prompted us to investigate the reaction of the palladacycles $3 \mathrm{a}-\mathrm{d}$ with isocyanate $\left(\mathrm{C}_{10} \mathrm{H}_{7}-\mathrm{NCO}\right)$ and isothiocyanate $\left(\mathrm{C}_{10} \mathrm{H}_{7}-\mathrm{NCS}\right)$, in order to generate compounds for biological evaluation. The premised for such a study stems from the modular nature, i.e. ease of synthesis of analogues for structure activity studies (SAR) of the presence of $N$-donor ligands, such as $N, N, N^{\prime}, N^{\prime}$ tetramethyl-ethane-1,2-diamine (TMEDA), (2,2'-bipyridine (bpy), (4,4'-dimethyl-2,2'-bipyridine (dmbpy) and 1,10-phenanthrroline (Phen), and the druglikeness of the ligands scaffold, which may lead to favorable properties in the resulting of some palladacycles complexes.

Based on the results described above, in the present paper, we investigated the interactions of cathepsin $\mathrm{B}$ with some palladacycles derived from the reaction of 2-Bromo-3,4,5-trimethoxybenzaldehyde 1 with $\left[\mathrm{Pd}_{2}(\mathrm{dba})_{3}\right] \cdot d b a\left(\mathrm{Pd}(\mathrm{dba})_{2} ; \mathrm{dba}=\right.$ dibenzylideneacetone $)$, in the presence of $N$-donor ligands, such as $N, N, N^{\prime}, N^{\prime}$-tetramethyl-ethane1,2-diamine (TMEDA), (2,2'-bipyridine (bpy), (4,4'-dimethyl-2,2'bipyridine (dmbpy) and 1,10-phenanthrroline (Phen). We concluded that the antitumor activity of the palladacycles compounds presented here can be attributed, at least in part, to the inhibitory properties of these complexes on the cysteine-protease activity, such as cathepsin B. Palladacycles are one of the most popular classes of organo palladium derivatives, which are widely applied in organic synthesis [24-39], organometallic catalysis [40-44], and new molecular materials [24]. Among them, the most investigated cyclic Pd-complexes are five- or six-membered rings fused with an aromatic ring, and the metallated carbon is usually an aromatic sp2 carbon [35-39]. However, sixmember cyclopalladated with 1-naphthylisocyanate- $(-\mathrm{N}=\mathrm{C}=\mathrm{O})$ and 1-naphthylisothiocyanate $(-\mathrm{N}=\mathrm{C}=\mathrm{S}), s p^{2}$ carbon are rather rare. This is probably due to poor stability, which brings difficulties of preparation, isolation and characterization of these compounds. The limitation can be overcome by changing the nature of the metallated carbon atom, the type of donor groups and their substituents. Some of these reactions involve ortho-functionalized aryl complexes that after insertion of isocyanates gave heterocyclic, which the ortho group is included. A few examples of insertion of isocyanates into some other orthofunctionalized aryl palladium (II) complexes, leading to heterocyclic compounds have also been reported. The interest of this subject has prompted us to prepare aryl palladium complexes containing ortho-$\mathrm{CHO}$ functionalized. Herein, we report our results describing the preparation and full characterization of novel palladacycles $3 \mathrm{a}-\mathrm{d}$. In this context, the methodology of the synthesis of aryl palladium complexes $3 \mathrm{a}$ - $\mathrm{d}$ was studied. The reactivity of these aryl palladium complexes towards bulky of 1-naphthylisocyanate- $(-\mathrm{N}=\mathrm{C}=\mathrm{O})$ and 1-naphthylisothiocyanate $(-\mathrm{N}=\mathrm{C}=\mathrm{S})$, depend on the nature of substitution and the reaction conditions. The products of these

*Corresponding author: Abdel-Sattar S Hamad Elgazwy, Department of Chemistry, Faculty of Science, Ain Shams University, Abbassia 11566, Cairo, Egypt, Tel/Fax: 002024831836; E-mail: elgazwy@sci.asu.edu.eg

Received July 22, 2013; Accepted August 29, 2013; Published August 30, 2013

Citation: Hamad Elgazwy ASS, Shehata MR, Zaki MY, Solima DHS, Elbakkry MM (2013) Synthesis of Novel Palladacycles Inhibitors of the Cathepsin B Activity and Antitumoral Agents. Med chem 3: 254-261. doi:10.4172/2161-0444.1000148

Copyright: (c) 2013 Hamad Elgazwy ASS, et al. This is an open-access article distributed under the terms of the Creative Commons Attribution License, which permits unrestricted use, distribution, and reproduction in any medium, provided the original author and source are credited. 
reactions are mono-inserted complexes and prepared in single solvent, and no diffraction- quality crystals were grown by slow diffusion of $\mathrm{Et}_{2} \mathrm{O}$ into a $\mathrm{CH}_{2} \mathrm{Cl}_{2}$ solution.

In addition to that, the electron releasing methoxyl groups $(\mathrm{MeO})_{3}$ of the side chain could confer special properties to the formyl group, for example, facilitating its coordination to metallic centers to give cyclometalated species. Finally, this aryl moiety is present in organic molecules of pharmaceutical interest. For example, the antileukemic lactones steganacin, steganangin $[45,46]$, the antibacterial agent trimethoprim [47], and the cytotoxic colchicines [48]. The cactus alkaloid, mescaline, beta-(3,4,5-trimethoxyphenyl)-ethylamine, has been studied for some years, because of its most interesting effects on the psychic states of human subjects. Since the elucidation of the chemical structure of the alkaloid through the synthesis by Spnth [49], a few other methods of preparation have been published [50,51].

The complexes exhibited growth inhibitory activity against L1210 mouse leukæmia cells in vitro over a wide concentration range; in general, the cyclometallated complexes were more active than the mixed ligand complexes, although one cyclometallated organoplatinum complex was less active than the mixed ligand analogue. Substitution around the periphery of the aromatic ligands also resulted in increased activity. One complex, derived from 1-(2'-pyridyl)indole, was tested in vivo and showed no significant antitumour inhibition against P388 leukæmia at doses below toxic levels [52-68].

\section{Experimental Procedure}

\section{General}

Starting materials and commercial grade solvents were purchased from Sigma-Aldrich or Alfa Aesar and used without further purification. Reactions were carried out under nitrogen. Vero cells were from the American Tissue Culture Collection, The B16 cells were kindly donated by Dr. Nadia (Cancer Institute' Hospital). Reactions were carried out without precautions to exclude atmospheric moisture, unless otherwise stated. The IR and C, H, N Elemental analyses and melting point determinations were carried out as described elsewhere [69]. NMR spectra were recorded on Varian Unity 300 and a Bruker Unity 200 instruments. Chemical shifts were referred to TMS $\left({ }^{1} \mathrm{H}\right.$ and $\left.{ }^{13} \mathrm{C}\left\{{ }^{1} \mathrm{H}\right\}\right)$-NMR assignments were made with the help of DEPT techniques. Chromatographic separations were carried out by TLC on silica gel 60 ACC (70-230 mesh). Complex of "Pd- $(\mathrm{dba})_{2}$ ” $\left(\left[\mathrm{Pd}_{2}(\mathrm{dba})_{3}\right]\right.$ $\mathrm{dba})$, was prepared as previously reported [70,71].

Synthesis of Cis- $\left[\mathrm{Pd}\left\{\mathrm{C} 6 \mathrm{H}(\mathrm{CHO})-6-\mathrm{OMe}_{3}-2,3,4\right\} \mathrm{Br}\left(\mathrm{L}_{2}\right)\right]$ d)

General methods: 2-bromo-3,4,5-trimethoxybenzaldehyde 1 (1.19 $\mathrm{mmol})$ was added to a suspension of "Pd(dba) ${ }_{2}$ (288 $\left.\mathrm{mg}, 0.5 \mathrm{mmol}\right)$ and $\mathrm{N}$-donor ligands $(0.5 \mathrm{mmol})$ in degassed acetone $(15 \mathrm{ml})$ under nitrogen, and the resulting mixture was stirred at $0^{\circ} \mathrm{C}$ for $30 \mathrm{mins}$, and continue stirring at room temperature for $3 \mathrm{~h}$. The solvent was evaporated in vacuo, the residue extracted with $\mathrm{CH}_{2} \mathrm{Cl}_{2}(20 \mathrm{~mL})$, and the resulting suspension filtered over anhydrous $\mathrm{MgSO}_{4}$. The solvent was concentrated to dryness and the resulting solid was separated by filtration, washed with $\mathrm{Et}_{2} \mathrm{O}(2 \times 20 \mathrm{~mL})$ and air-dried to give $3 \mathrm{a}-\mathrm{d}$ as a yellow solid and air dried.

Cis-[Pd $\left\{\mathrm{C6H}(\mathrm{CHO})-6-\mathrm{OMe}_{3}-2,3,4\right\} \mathrm{Br}$ (tmeda)] (3a): Yellow solid, Yield: $300 \mathrm{mg}, 60 \%$. Mp: $178-180^{\circ} \mathrm{C} \mathrm{dec}$. IR $\left(\mathrm{cm}^{-1}\right)(\mathrm{KBr}), \mathrm{v}(\mathrm{CO})$, 1670, 1578, 1465, 1419, 1365, 1315, 1265, 1193, 1154, 1099, 1065, 1012, 805, 771, 725. ${ }^{1} \mathrm{H}$ NMR (300 MHz, DMSO): $\delta$ at 2.29 (S, 3H, -NMe), 2.54 (S, 3H, -NMe), 2.68(S, 3H, -NMe), 2.73 (S, 3H, -NMe), 2.55-2.80 (m, 4H, - $\left.\mathrm{CH}_{2}-\mathrm{CH}_{2}-\right), 3.83$ (S, 3H, OMe), 3.95 (S, 3H, OMe), 4.22 (S $3 \mathrm{H}, \mathrm{OMe}), 7.19\left(\mathrm{~S}, 1 \mathrm{H}, \mathrm{C}_{6} \mathrm{H}_{1}\right), 11.15(\mathrm{~S}, 1 \mathrm{H}, \mathrm{CHO}) .{ }^{13} \mathrm{C}-\mathrm{NMR}$ (DMSO, $75 \mathrm{MHz}) ; \delta$ at $47.96,48.32,51.07,52.10\left(\mathrm{NMe}_{2}\right)_{2}$; 55.9, 58.74, 60.9, $61.02,106.52,136.36,143.32,146049,151.14,155.53,195.89$ (CHO). LRMS (EI): m/z: 498.02 [ ( $\left.\left.\left.\mathrm{M}^{+}+2\right), 100.0 \%\right)\right], 496.02$ (73.5\%), 500.02 (66.6\%), 497.02 (50.1\%), 495.02 (42.6\%), 494.02 (21.1\%), 502.02 (21.1\%), 499.02 (16.9\%), 501.02 (11.7\%), 503.02 (3.7\%), 492.02 (1.8\%).; GC: $t_{R}=7.914 \mathrm{~min}$; column: DB- $56 \mathrm{~m} \times 0.01 \mathrm{~mm}+1 \mathrm{~m}$ guard column: temp. prog. $50^{\circ} \mathrm{C} / 2 \mathrm{~min} . / 20^{\circ} \mathrm{C} / 1 \mathrm{~min} . / 325^{\circ} \mathrm{C} / 10 \mathrm{~min}$; Anal. Calcd for $\mathrm{C}_{16} \mathrm{H}_{27} \mathrm{~N}_{2} \mathrm{BrPdO}_{4}$ (497.72): C, 38.61; H, 5.47; N, 5.63 Found: C, 38.31; $\mathrm{H}, 5.40 ; \mathrm{N}, 5.62$.

Cis-[Pd $\{\mathrm{C6H}(\mathrm{CHO})-6-\mathrm{OMe}-2,3,4\} \mathrm{Br}(\mathrm{bpy})] \quad$ (3b): Brownish green powder, Yield: $257 \mathrm{mg}, 48 \%$. Mp: $144-146^{\circ} \mathrm{C}$ dec.; IR $\left(\mathrm{cm}^{-1}\right)$ (KBr), v(C=O, aldehyde), 1674; ${ }^{1} \mathrm{H}$ NMR (300 MHz, DMSO): $\delta, 11.12$ (s, 1H, CHO), $9.13\left(\mathrm{~d}, 1 \mathrm{H}, \mathrm{bpy},{ }^{1,3} J_{H H}=5.1 \mathrm{~Hz}\right), 8.68\left(\mathrm{~d}, 1 \mathrm{H}, \mathrm{bpy},{ }^{1,3} J_{H H}\right.$ $=5.1 \mathrm{~Hz}), 8.57\left(\mathrm{~d}, 1 \mathrm{H}, \mathrm{bpy},{ }^{1,3} J_{H \mathrm{H}}=6.9 \mathrm{~Hz}\right), 8.39-8.32(\mathrm{~m}, 2 \mathrm{H}, \mathrm{bpy}), 7.97-$ 7.91 (m, 1H, bpy), 7.83-7.78 (m, 1H, bpy), 7.47-7.42 (m, 1H, bpy), 7.02 (s, $\mathrm{C} 6 \mathrm{H1}, 1 \mathrm{H}), 4.12$ (s, OMe, 3H), 3.77 (s, OMe, 3H), 3.73 (s, OMe, 3H); LRMS (EI): m/z: 535.96 [( $\left.\left.\left.\mathrm{M}^{+}-1\right), 100.0 \%\right)\right], 537.96\left[\left(\mathrm{M}^{+}+2\right),(99.5 \%)\right]$, 536.96 (94.6\%), 537.95 (82.0\%), 539.95 (79.0\%), 534.96 (76.6\%), 539.96 (41.2\%), 541.96 (38.7\%), 538.96 (38.2\%), 533.96 (37.2\%), 535.95 (33.7\%), 540.96 (26.0\%), $542.96(8.0 \%), 531.96$ (3.1\%), $538.95(1.2 \%)$, 543.96 (1.1\%). GC: $t_{R}=6.814 \mathrm{~min}$; column: DB-5 $6 \mathrm{~m} \times 0.01 \mathrm{~mm}+1 \mathrm{~m}$ guard column: temp. prog. $50^{\circ} \mathrm{C} / 2 \mathrm{~min} / 20^{\circ} \mathrm{C} / 1 \mathrm{~min} / 325^{\circ} \mathrm{C} / 10 \mathrm{~min}$; Anal. Calcd for $\mathrm{C}_{20} \mathrm{H}_{19} \mathrm{BrN}_{2} \mathrm{O}_{4} \mathrm{Pd}$ (537.70); C, 44.67; H, 3.56; N, 5.21; Found: C, 45.01; H, 4.08; N, 5.22.

Cis-[Pd $\{\mathrm{C6H}(\mathrm{CHO})-6-\mathrm{OMe} 3-2,3,4\} \mathrm{Br}(\mathrm{dmbpy})] \quad$ (3c): Brown powder, Yield: $288 \mathrm{mg}, 51 \%$. Mp:282-284 ${ }^{\circ} \mathrm{C}$ dec. IR $\left(\mathrm{cm}^{-1}\right)(\mathrm{KBr})$, $\mathrm{v}(\mathrm{C}=\mathrm{O}$, aldehyde $), 1673,1574,1466,1419,1361,1265,1099,1010$, 802.; ${ }^{1} \mathrm{H}$ NMR (300 MHz, DMSO): $\delta 11.12(\mathrm{~s}, 1 \mathrm{H}, \mathrm{CHO}), 8.80(\mathrm{~d}$, $1 \mathrm{H}, \mathrm{Me}_{2} \mathrm{bpy},{ }^{1,3} \mathrm{~J}_{\mathrm{HH}}=5.7 \mathrm{~Hz}$ ), 8.36 (s, $\left.2 \mathrm{H}, \mathrm{Me}_{2} \mathrm{bpy}\right), 7.45\left(\mathrm{~d}, 2 \mathrm{H}, \mathrm{Me}_{2} \mathrm{bpy}\right.$, $\left.{ }^{1,3} J_{H H}=5.7 \mathrm{~Hz}\right), 7.13(\mathrm{~s}, \mathrm{C} 6 \mathrm{H1}, 1 \mathrm{H}), 4.14$ (s, OMe, 3H), 3.80 (s, OMe, 3H), 3.75 (s, OMe, 3H), 2.49 (s, 2Me, 6H); LRMS (EI): m/z: 565.99 $\left.\left.\left[\left(\mathrm{M}^{+}+2\right), 100.0 \%\right)\right], 563.99\left[\left(\mathrm{M}^{+}-2\right), 73.9 \%\right)\right], 567.99$ (66.1\%), 564.99 (52.2\%), 562.99 (42.4\%), 566.99 (23.2\%), 569.99 (20.9\%), 561.99 (20.3\%), 568.99 (15.4\%), 570.99 (4.7\%), 559.99 (1.7\%), 565.00 (1.1\%); GC: $t_{R}=7.714 \mathrm{~min}$; column: $\mathrm{DB}-56 \mathrm{~m} \times 0.01 \mathrm{~mm}+1 \mathrm{~m}$ guard column: temp. prog. $50^{\circ} \mathrm{C} / 2 \mathrm{~min} / 20^{\circ} \mathrm{C} / 1 \mathrm{~min} / 325^{\circ} \mathrm{C} / 10 \mathrm{~min}$; Anal. Calcd for $\mathrm{C}_{22} \mathrm{H}_{23} \mathrm{BrN}_{2} \mathrm{O}_{4} \mathrm{Pd}$ (565.75); C, 46.71; H, 4.10; N, 4.95; Found: C, 47.20; $\mathrm{H}, 3.97 ; \mathrm{N}, 4.99$.

Cis-[Pd $\left\{\mathrm{C}_{6} \mathrm{H}(\mathrm{CHO})-6-\mathrm{OMe}_{3}-2,3,4\right\} \mathrm{Br}($ phen $\left.)\right]$ (3d): Brown solid, Yield: $298 \mathrm{mg}, 53 \%$. Mp: $198-200^{\circ} \mathrm{C} \mathrm{dec}$. IR $\left(\mathrm{cm}^{-1}\right)(\mathrm{KBr}), \mathrm{v}(\mathrm{C}=\mathrm{O}$, aldehyde), 1672, 1542, 1422, 1340, 1148, 1106, 842, 711, 463.; ${ }^{1} \mathrm{H}$ NMR (DMSO, $300 \mathrm{MHz}$ ): $11.18(\mathrm{a}, \mathrm{CHO}, 1 \mathrm{H}), 9.57$ (dd, phen, $1 \mathrm{H},{ }^{1,3} \mathrm{~J}_{\mathrm{HH}}=5$ and $1.5 \mathrm{~Hz}), 8.57\left(\mathrm{dd}\right.$, phen, $1 \mathrm{H},{ }^{1.3} J_{H H}=8$ and $\left.1.5 \mathrm{~Hz}\right), 8.48(\mathrm{dd}$, phen, 1 $\mathrm{H},{ }^{1,3} \mathrm{~J}_{\mathrm{HH}}=8$ and $\left.1.4 \mathrm{~Hz}\right), 7.9-8.1(\mathrm{~m}$, phen, $4 \mathrm{H}), 7.60(\mathrm{dd}$, phen, $1 \mathrm{MeO})$.; LRMS (EI): $\left.\mathrm{m} / \mathrm{z}: 559.96\left[\left(\mathrm{M}^{+}+1\right), 100.0 \%\right)\right], 561.96$ [( $\left.\left.\left.\mathrm{M}^{+}-2\right), 99.9 \%\right)\right]$, 560.96 (95.8\%), 561.95 (80.6\%), 563.95 (77.7\%), 558.96 (76.1\%), 562.96 (41.4\%), 563.96 (41.4\%), 565.96 (38.6\%), 557.96 (36.6\%), 559.95 (33.2\%), 564.96 (28.1\%), 566.96 (8.6\%), 555.96 (3.1\%), $567.96(1.3 \%)$, 562.95 (1.2\%).; GC: $t_{R}=7.925 \mathrm{~min}$; column: DB-5 $6 \mathrm{~m} \times 0.01 \mathrm{~mm}+1 \mathrm{~m}$ guard column: temp. prog. $50^{\circ} \mathrm{C} / 2 \mathrm{~min} / 22^{\circ} \mathrm{C} / 1 \mathrm{~min} / 325^{\circ} \mathrm{C} / 10 \mathrm{~min}$; Anal. Calcd for $\mathrm{C}_{22} \mathrm{H}_{19} \mathrm{BrN}_{2} \mathrm{O}_{4} \mathrm{Pd}$ (561.72); C, 47.04; H, 3.41; N, 4.99. Found C, 46.89; H, 4.02; N, 4.88 .

\section{Reaction with bulky naphthylisocyanate and naphthyliso- thiocycnate}

4.3.1) General methods reaction with naphthylisocyanate: Cis$\left[\mathrm{Pd}\left\{\mathrm{C}_{6} \mathrm{H}(\mathrm{CHO})-6-\mathrm{OMe}_{3}-2,3,4\right\} \mathrm{Br}(\mathrm{L}) 2\right] 3 \mathrm{a}-\mathrm{d}(0.1 \mathrm{mmol})$ was added to a suspension of naphthylisocyanate $(14 \mu \mathrm{l}, 0.1 \mathrm{mmol})$ in dry toluene 
$(15 \mathrm{ml})$, and the resulting mixture was refluxing for $3 \mathrm{~h}$. The solvent was concentrated to dryness and the resulting solid was separated by filtration, washed with $\mathrm{Et}_{2} \mathrm{O}(2 \times 20 \mathrm{~mL})$ and air-dried to give $4 \mathrm{a}-\mathrm{d}$ as a yellow solid and air dried.

6,7,8-trimethoxy-2-naphthyl-2,3-dihydroisoquinoline-1,4dione -3-Pd [TMEDA] (4a): Cis- $\left[\mathrm{Pd}\left\{\mathrm{C}_{6} \mathrm{H}(\mathrm{CHO})-6-\mathrm{OMe}_{3}-2,3,4\right\}\right.$ $\mathrm{Br}(\mathrm{L}) 2] \mathrm{a}$ (50 mg, $0.1 \mathrm{mmol})$ was added to a suspension of naphthyl1-isocyanate $(14 \mu \mathrm{l}, 0.1 \mathrm{mmol})$ in dry toluene $(15 \mathrm{ml})$, and the resulting mixture was refluxing for $3 \mathrm{~h}$. The solvent was concentrated to dryness and the resulting solid was separated by filtration, washed with $\mathrm{Et}_{2} \mathrm{O}$ $(2 \times 20 \mathrm{~mL})$ and air-dried to give a grey solid of $4 \mathrm{a}$, yield; $41 \mathrm{mg}, 70 \%$ .Mp: $210-212^{\circ} \mathrm{C}$ dec. IR $\left(\mathrm{cm}^{-1}\right)(\mathrm{KBr}), \mathrm{v}(\mathrm{NH}), 3274, \mathrm{v}(\mathrm{C}=\mathrm{O}, 1660,1542$, 1422, 1340, 1148, 1106, 842, 711, 463; ${ }^{1} \mathrm{H}$ NMR (DMSO, $300 \mathrm{MHz}$ ): $\delta$ 8.25 (d, naphthyl, $1 \mathrm{H},{ }^{1,3} \mathrm{~J}_{\mathrm{HH}}=7.8 \mathrm{~Hz}$ ), $8.17\left(\mathrm{~d}\right.$, naphthyl, $1 \mathrm{H},{ }^{1,3} J_{H \mathrm{H}}=7.5$ $\mathrm{Hz}$ ), 7.85 (d, naphthyl, $1 \mathrm{H},{ }^{1,3} J_{\mathrm{HH}}=8.4 \mathrm{~Hz}$ ), 7.67-7.30 (m, naphthyl, 4H), 6.98 (s, C6H1, 1H), 3.78 (S, 3H, OMe), 3.76 (S, 3H, OMe), 3.73 (S, 3H, - OMe), 3.68-3.64 (m, 4H, - $\left.\mathrm{CH}_{2}-\mathrm{CH}_{2}-\right), 2.9\left(\mathrm{~S}, 12 \mathrm{H},\left(-\mathrm{NMe}_{2}\right)_{2}\right]$.

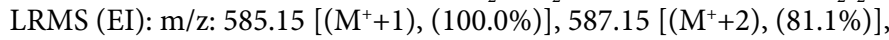
584.15 (74.1\%), 589.15 (38.1\%), 583.15 (32.4\%), 586.15 (27.2\%), 588.15 (23.1\%), 590.15 (10.4\%), 581.15 (2.9\%), 591.15 (1.9\%).; GC: $t_{R}=7.925$ min; column: DB-5 $6 \mathrm{~m} \times 0.01 \mathrm{~mm}+1 \mathrm{~m}$ guard column: temp. prog. $50^{\circ} \mathrm{C} / 2 \mathrm{~min} / 22^{\circ} \mathrm{C} / 1 \mathrm{~min} / 325^{\circ} \mathrm{C} / 10 \mathrm{~min}$; Anal. Calcd for $\mathrm{C}_{27} \mathrm{H}_{33} \mathrm{~N}_{3} \mathrm{O}_{5} \mathrm{Pd}$ (585.99): C, 55.34; H, 5.68; N, 7.17 Found: C, 55.45; H, 5.61; N, 7.19.

6,7,8-trimethoxy-2-naphthyl-2,3-dihydroisoquinoline-1,4dione -3-Pd [bpy] (4b): Orang solid of 4b, yield; 55 mg, 60\% .Mp: 250$252^{\circ} \mathrm{C}$ dec. IR $\left(\mathrm{cm}^{-1}\right)(\mathrm{KBr}), \mathrm{v}(\mathrm{NH}), 3277, \mathrm{v}(\mathrm{C}=\mathrm{O}, 1665,1542,1422$, 1340, 1148, 1106, 842, 711, 463; ${ }^{1} \mathrm{H}$ NMR (DMSO, $\left.300 \mathrm{MHz}\right): \delta 9.33$ $\left(\mathrm{d}, 2 \mathrm{H}, \mathrm{bpy},{ }^{1,3} \mathrm{~J}_{\mathrm{HH}}=5.1 \mathrm{~Hz}\right), 9.18\left(\mathrm{~d}, 2 \mathrm{H}, \mathrm{bpy},{ }^{1,3} \mathrm{~J}_{\mathrm{HH}}=5.1 \mathrm{~Hz}\right), 8.78(\mathrm{~d}$, $\left.2 \mathrm{H}, \mathrm{bpy},{ }^{1,3} \mathrm{~J}_{\mathrm{HH}}=6.9 \mathrm{~Hz}\right), 8.59-8.32(\mathrm{~m}, 2 \mathrm{H}, \mathrm{bpy}), 7.94$ (d, naphthyl, $1 \mathrm{H}$, ${ }^{1,3} J_{H H}=7.8 \mathrm{~Hz}$ ), $7.78\left(\mathrm{~d}\right.$, naphthyl, $\left.1 \mathrm{H},{ }^{1,3} J_{H H}=7.55 \mathrm{~Hz}\right), 7.94$ (d, naphthyl, $\left.1 \mathrm{H},{ }^{1,3} J_{H H}=8.4 \mathrm{~Hz}\right), 7.72-7.52(\mathrm{~m}$, naphthyl, $4 \mathrm{H}), 7.05$ (s, C6H1, $\left.1 \mathrm{H}\right), 3.78$ (S, 3H, OMe), 3.75 (S, 3H, OMe), 3.73 (s, 3H, OMe,); LRMS (EI): m/z: $625.08\left[\left(\mathrm{M}^{+}+1\right),(100.0 \%)\right], 627.08\left[\left(\mathrm{M}^{+}+2\right),(96.2 \%)\right], 624.08(81.3 \%)$, 629.08 (42.8\%), 623.08 (40.3\%), 626.09 (39.4\%), 628.09 (33.6\%), 625.09 (30.2\%), 630.09 (15.4\%), 624.09 (13.7\%), 627.09 (7.4\%), 629.09 (6.4\%), 621.09 (3.7\%), 631.09 (2.9\%), 626.08 (1.4\%), 622.09 (1.3\%), 628.08 (1.1\%).; GC: $t_{R}=7.925 \mathrm{~min}$; column: DB-5 $6 \mathrm{~m} \times 0.01 \mathrm{~mm}+1 \mathrm{~m}$ guard column: temp. prog. $50^{\circ} \mathrm{C} / 2 \mathrm{~min} / 22^{\circ} \mathrm{C} / 1 \mathrm{~min} / 325^{\circ} \mathrm{C} / 10 \mathrm{~min}$; Anal. Calcd for $\mathrm{C}_{31} \mathrm{H}_{25} \mathrm{~N}_{3} \mathrm{O}_{5} \mathrm{Pd}$ (625.97): C, 59.48; H, 4.03; N, 6.71 Found: C, $59.54 ; \mathrm{H}, 4.22 ; \mathrm{N}, 6.75$.

6,7,8-trimethoxy-2-naphthyl-2,3-dihydroisoquinoline-1,4dione -3-Pd [dmbpy] (4c): Brown powder, Yield: $80 \mathrm{mg}, 58 \% . \mathrm{Mp}$ : $272-274^{\circ} \mathrm{C}$ dec. IR $\left(\mathrm{cm}^{-1}\right)(\mathrm{KBr}), \mathrm{v}(\mathrm{NH}), 3277, \mathrm{v}(\mathrm{C}=\mathrm{O}, 1673,1574$, 1466, 1419, 1361, 1265, 1099, 1010, 802.; ${ }^{1} \mathrm{H}$ NMR (300 MHz, DMSO): $\delta, 9.36$ (s, $2 \mathrm{H}, \mathrm{Me}_{2} \mathrm{bpy}$ ), 9.05 (d, 2H, Me ${ }_{2} \mathrm{bpy},{ }^{1,3} \mathrm{H}_{\mathrm{H}}=5.7 \mathrm{~Hz}$ ), 8.65 (d, $2 \mathrm{H}$, $\mathrm{Me}_{2}$ bpy, ${ }^{1,3} J_{H H}=5.7 \mathrm{~Hz}$ ), 8.25 (d, naphthyl, $\left.1 \mathrm{H},{ }^{1,3} J_{H H}=7.8 \mathrm{~Hz}\right), 8.07$ (d, naphthyl, $1 \mathrm{H},{ }^{1,3} J_{H H}=7.5 \mathrm{~Hz}$ ), 7.95 (d, naphthyl, $\left.1 \mathrm{H},{ }^{1,3} J_{H H}=8.4 \mathrm{~Hz}\right), 7.67-$ 7.49 (m, naphthyl, 4H), 7.13 (s, C6H1, 1H), 3.79 (s, OMe, 3H), 3.75 (s, OMe, 3H), 3.73 (s, OMe, 3H), 2.39 (s, 6H ,2Me); LRMS (EI): m/z: $\left.653.11\left[\left(\mathrm{M}^{+}+1\right), 100.0 \%\right)\right], 655.11\left[\left(\mathrm{M}^{+}+2\right),(96.3 \%)\right], 652.12(95.6 \%)$, 657.12 (50.0\%), 654.12 (42.6\%), $651.11(40.4 \%), 656.12(35.9 \%)$, 653.12 (32.5\%), 658.12 (16.5\%), 655.12 (7.7\%), 649.12 (3.7\%), 659.12 (3.3\%), 650.12 (1.3\%), 654.11 (1.1\%), 656.11 (1.1\%); GC: $t_{R}=7.925$ min; column: DB-5 $6 \mathrm{~m} \times 0.01 \mathrm{~mm}+1 \mathrm{~m}$ guard column: temp. prog. $50^{\circ} \mathrm{C} / 2 \mathrm{~min} / 22^{\circ} \mathrm{C} / 1 \mathrm{~min} / 325^{\circ} \mathrm{C} / 10 \mathrm{~min}$; Anal. Calcd for $\mathrm{C}_{33} \mathrm{H}_{29} \mathrm{~N}_{3} \mathrm{O}_{5} \mathrm{Pd}$ (654.02): C, 60.60; H, 4.47; N, 6.42 Found: C, 60.54; H, 4.62; N, 6.55.

6,7,8-trimethoxy-2-naphthyl-2,3-dihydroisoquinoline-1,4dione -3-Pd [phen] (4d): Brown solid, Yield: $298 \mathrm{mg}, 53 \%$. Mp: $292-$ $294^{\circ} \mathrm{C} \mathrm{dec}$. IR $\left(\mathrm{cm}^{-1}\right)(\mathrm{KBr}), \mathrm{v}(\mathrm{C}=\mathrm{O}, 1672,1542,1422,1340,1148,1106$,
842, 711, 463.; ${ }^{1} \mathrm{H}$ NMR (DMSO, $300 \mathrm{MHz}$ ): $\delta 9.37$ (dd, phen, $2 \mathrm{H}$ ${ }^{1,3} J_{H H}=5$ and $1.5 \mathrm{~Hz}$ ), $9.27\left(\mathrm{dd}\right.$, phen, $2 \mathrm{H},{ }^{1.3} \mathrm{~J}_{\mathrm{HH}}=8$ and $\left.1.5 \mathrm{~Hz}\right), 8.48$ (dd, phen, $2 \mathrm{H},{ }^{1,3} J_{H H}=8$ and $1.4 \mathrm{~Hz}$ ), 8.25 (d, naphthyl, $1 \mathrm{H},{ }^{1,3} J_{H H}=7.8$ $\mathrm{Hz}$ ), 8.07 (d, naphthyl, $1 \mathrm{H},{ }^{1,3} \mathrm{~J}_{\mathrm{HH}}=7.5 \mathrm{~Hz}$ ), 7.9-8.1 (m, $2 \mathrm{H}$, phen), 7.95 (d, naphthyl, $\left.1 \mathrm{H},{ }^{1,3} J_{H H}=8.4 \mathrm{~Hz}\right), 7.67-7.49(\mathrm{~m}$, naphthyl, $4 \mathrm{H}), 7.27(\mathrm{~s}$ C6H1, 1H), 3.77 (s, OMe, 3H), 3.75 (s, OMe, 3H), 3.73 (s, OMe, 3H).; LRMS (EI): $\mathrm{m} / \mathrm{z}: 649.08$ [( $\left.\left.\mathrm{M}^{+}+1\right),(100.0 \%)\right], 651.08$ [( $\left.\left.\mathrm{M}^{+}+2\right),(96.2 \%)\right]$, 648.08 (81.3\%), 653.08 (42.8\%), 650.09 (42.2\%), 647.08 (40.3\%), 652.09 (35.8\%), 649.09 (32.2\%), 654.09 (16.4\%), 648.09 (14.6\%), 651.09 (8.3\%), 653.09 (7.1\%), 645.09 (3.7\%), 655.09 (3.2\%), 650.08 (1.4\%), 646.09 (1.3\%), 652.08 (1.1\%).; GC: $t_{R}=7.925 \mathrm{~min}$; column: DB-5 6 $\mathrm{m} \times 0.01 \mathrm{~mm}+1 \mathrm{~m}$ guard column: temp. prog. $50^{\circ} \mathrm{C} / 2 \mathrm{~min} / 22^{\circ} \mathrm{C} / 1$ min. $/ 325^{\circ} \mathrm{C} / 10 \mathrm{~min}$; Anal. Calcd for $\mathrm{C}_{23} \mathrm{H}_{25} \mathrm{~N}_{3} \mathrm{O}_{5} \mathrm{Pd}$ (649.99); C, 60.98; $\mathrm{H}, 3.88 ; \mathrm{N}, 6.46$. Found $\mathrm{C}, 60.89 ; \mathrm{H}, 3.92 ; \mathrm{N}, 6.58$.

\section{Reaction with naphthylisothiocycnate}

General methods: Cis- $\left[\mathrm{Pd}\left\{\mathrm{C}_{6} \mathrm{H}(\mathrm{CHO})-6-\mathrm{OMe}_{3}-2,3,4\right\} \mathrm{Br}(\mathrm{L}) 2\right]$ 3a-d $(0.1 \mathrm{mmol})$ was added to a suspension of naphthylisothiocyanate $(14 \mu \mathrm{l}, 0.1 \mathrm{mmol})$ in dry toluene $(15 \mathrm{ml})$, and the resulting mixture was refluxing for $3 \mathrm{~h}$. The solvent was concentrated to dryness and the resulting solid was separated by filtration, washed with $\mathrm{Et}_{2} \mathrm{O}(2 \times 20$ $\mathrm{mL}$ ), and air-dried to give $5 \mathrm{a}-\mathrm{d}$ as a yellow solid and air dried.

(1Z)-6,7,8-trimethoxy-1-(naphthylimino)-1H-isothiochromen4(3H)-one-3-Pd[TMEDA] (5a): Grey solid, yield; $41 \mathrm{mg}, 70 \%$.Mp: $282-284^{\circ} \mathrm{C} \mathrm{dec}$. IR $\left(\mathrm{cm}^{-1}\right)(\mathrm{KBr}), \mathrm{v}(\mathrm{NH}), 3274, \mathrm{v}(\mathrm{C}=\mathrm{O}, 1660, \mathrm{v}(\mathrm{C}=\mathrm{N}$, 1580, v(C=S, 1310; v(C-S, 1100, 1542, 1422, 1340, 1148, 1106, 842, 711, 463; ${ }^{1} \mathrm{H}$ NMR (DMSO, $300 \mathrm{MHz}$ ): 8.02 (d, naphthyl, $1 \mathrm{H},{ }^{1,3} \mathrm{~J}_{\mathrm{HH}}=7.8 \mathrm{~Hz}$ ), 7.89 (d, naphthyl, $1 \mathrm{H},{ }^{1,3} J_{H H}=7.5 \mathrm{~Hz}$ ), 7.75 (d, naphthyl, $1 \mathrm{H},{ }^{1,3} J_{H H}=8.4$ $\mathrm{Hz})$, 7.62-7.49 (m, naphthyl, 4H), 6.82 (s, C6H1, 1H), 3.77 [(S, 9H, $\left.(-\mathrm{OMe})_{3}\right], 3.68-3.66\left(\mathrm{~m}, 4 \mathrm{H},-\mathrm{CH}_{2}-\mathrm{CH}_{2}-\right), 2.93$ [(S, 12H, $\left.\left(-\mathrm{NMe}_{2}\right)_{2}\right]$; ${ }^{13} \mathrm{C}-\mathrm{NMR}$ (DMSO,75 MHz); $\delta$, at 47.96, 48.32, 51.07, $52.10\left(\mathrm{NMe}_{2}\right)_{2}$; 55.9, 58.74, 60.9, 61.02, 106.52, 136.36, 143.32, 146049, 151.14, 155.53, 195.89 (CHO).LRMS (EI): m/z: $601.12\left[\left(\mathrm{M}^{+}+1\right),(100.0 \%), 603.12\right.$ $\left[\left(\mathrm{M}^{+}+2\right),(99.3 \%)\right], 600.12(79.7 \%), 605.12(46.0 \%), 599.12(39.5 \%)$ 602.13 (33.2\%), 604.13 (28.7\%), 601.13 (25.6\%), 606.13 (13.0\%), 600.13 (11.7\%), 602.12 (6.2\%), 603.13 (5.8\%), 605.13 (5.2\%), $597.12(3.6 \%)$, 604.12 (3.2\%), 607.13 (2.4\%), $606.12(2.1 \%), 607.12$ (2.1\%), 598.13 (1.1\%). GC: $t_{R}=7.925 \mathrm{~min}$; column: $\mathrm{DB}-56 \mathrm{~m} \times 0.01 \mathrm{~mm}+1 \mathrm{~m}$ guard column: temp. prog. $50^{\circ} \mathrm{C} / 2 \mathrm{~min} / 22^{\circ} \mathrm{C} / 1 \mathrm{~min} / 325^{\circ} \mathrm{C} / 10 \mathrm{~min}$; Anal Calcd for $\mathrm{C}_{27} \mathrm{H}_{33} \mathrm{~N}_{3} \mathrm{O}_{5} \mathrm{PdS}(602,05)$ : C, 53.86; H, 5.52; N, 6.98; $\mathrm{S}, 5.33$. Found: C, 53.85; H, 5.61; N, 6.99; S, 5.45.

(1Z)-6,7,8-trimethoxy-1-(naphthylimino)-1H-isothiochromen4(3H)-one-3-Pd[bpy] (5b): Orang solid of 5b, yield; $55 \mathrm{mg}, 60 \% \mathrm{Mp}$ $297-299^{\circ} \mathrm{C}$ dec. IR $\left(\mathrm{cm}^{-1}\right)(\mathrm{KBr}), \mathrm{v}(\mathrm{NH}), 3277, \mathrm{v}(\mathrm{C}=\mathrm{O}, 1665,1542,1422$, 1340, 1148, 1106, 842, 711, 463; ${ }^{1} \mathrm{H}$ NMR (DMSO, $300 \mathrm{MHz}$ ): $\delta 9.35$ (d, $\left.2 \mathrm{H}, \mathrm{bpy},{ }^{1,3} \mathrm{~J}_{\mathrm{HH}}=6.9 \mathrm{~Hz}\right), 9.14\left(\mathrm{dd}, 2 \mathrm{H}, \mathrm{bpy},{ }^{1,3} \mathrm{~J}_{\mathrm{HH}}=6.9\right.$ and $\left.5.1 \mathrm{~Hz}\right), 8.72$ (d, $2 \mathrm{H}$, bpy, ${ }^{1,3} \mathrm{~J}_{\mathrm{HH}}=5.1 \mathrm{~Hz}$ ), 8.53 (bs, $\left.2 \mathrm{H}, \mathrm{bpy}\right), 8.33$ (d, naphthyl, $1 \mathrm{H}$, ${ }^{1,3} J_{H H}=7.8 \mathrm{~Hz}$ ), 8.22 (d, naphthyl, $1 \mathrm{H},{ }^{1,3} J_{H H}=7.55 \mathrm{~Hz}$ ),7.85 (d, naphthyl, $1 \mathrm{H},{ }^{1,3} J_{H H}=8.4 \mathrm{~Hz}$ ), 7.39 (bs, naphthyl, $\left.4 \mathrm{H}\right), 6.85$ (s, C6H1, 1H), 3.89 (S, 3H, OMe), 3.84 (S, 3H, OMe), 3.77 (s, 3H, OMe); LRMS (EI): m/z: $643.06\left[\left(\mathrm{M}^{+}+1\right),(100.0 \%), 641.06\left[\left(\mathrm{M}^{+}-2\right),(99.8 \%)\right], 640.06(92.4 \%)\right.$, 645.06 (47.0\%), 639.06 (39.3\%), 642.06 (38.8\%), 644.06 (34.9\%), 641.07 (28.8\%), 646.07 (14.9\%), 643.07 (6.2\%), 642.07 (5.7\%), 645.07 (5.3\%), $637.06(3.6 \%), 647.07(2.8 \%), 647.06(2.4 \%), 646.06(2.3 \%), 644.07$ (1.2\%), 638.07 (1.2\%) GC: $t_{R}=7.925 \mathrm{~min}$; column: DB- $56 \mathrm{~m} \times 0.01 \mathrm{~mm}+1$ $\mathrm{m}$ guard column: temp. prog. $50^{\circ} \mathrm{C} / 2 \mathrm{~min} / 22^{\circ} \mathrm{C} / 1 \mathrm{~min} / 325^{\circ} \mathrm{C} / 10 \mathrm{~min}$; Anal. Calcd for $\mathrm{C}_{31} \mathrm{H}_{25} \mathrm{~N}_{3} \mathrm{O}_{4} \mathrm{PdS}$ (642.03): C, 57.99; H, 3.92; N, 6.54; , 4.99.; Found: C, 59.54; H, 4.22; N, 6.75; S, 5.01 .

(1Z)-6,7,8-trimethoxy-1-(naphthylimino)-1H-isothiochromen4(3H)-one-3-Pd[dmbpy] (5c): Brown powder, Yield: $80 \mathrm{mg}, 58 \%$. 
$\mathrm{Mp}:>300^{\circ} \mathrm{C}$ dec. IR $\left(\mathrm{cm}^{-1}\right)(\mathrm{KBr}), \mathrm{v}(\mathrm{NH}), 3277, \mathrm{v}(\mathrm{C}=\mathrm{O}, 1673,1574$, 1466, 1419, 1361, 1265, 1099, 1010, 802.; ${ }^{1} \mathrm{H}$ NMR (300 MHz, DMSO): $\delta 8.80\left(\mathrm{~d}, 1 \mathrm{H}, \mathrm{Me}_{2} \mathrm{bpy},{ }^{1,3} \mathrm{~J}_{\mathrm{HH}}=5.7 \mathrm{~Hz}\right), 8.36\left(\mathrm{~s}, 2 \mathrm{H}, \mathrm{Me}_{2} \mathrm{bpy}\right), 8.25$ (d, naphthyl, $\left.1 \mathrm{H},{ }^{1,3} J_{H H}=7.8 \mathrm{~Hz}\right), 8.07$ (d, naphthyl, $\left.1 \mathrm{H},{ }^{1,3} J_{H H}=7.5 \mathrm{~Hz}\right), 7.95$ (d, naphthyl, $\left.1 \mathrm{H},{ }^{1,3} J_{H H}=8.4 \mathrm{~Hz}\right), 7.67-7.49$ (m, naphthyl, $\left.4 \mathrm{H}\right), 7.45(\mathrm{~d}$, $\left.2 \mathrm{H}, \mathrm{Me}_{2} \mathrm{bpy},{ }^{1,3} \mathrm{~J}_{\mathrm{HH}}=5.7 \mathrm{~Hz}\right), 7.03$ (s, C6H1, $\left.1 \mathrm{H}\right), 4.14$ (s, OMe, 3H), 3.80 (s, OMe, 3H), 3.75 (s, OMe, 3H), 2.49 (s, 2Me, 6H). LRMS (EI): m/z: $669.09\left[\left(\mathrm{M}^{+}+1\right),(100.0 \%)\right], 671.09\left[\left(\mathrm{M}^{+}+2\right)(99.9 \%)\right], 668.09(79.6 \%)$, 673.09 (46.6\%), 670.09 (40.8\%), 667.09 (39.5\%), 672.10 (35.2\%), 669.10 (31.3\%), 674.10 (16.1\%), 668.10 (14.3\%), 671.10 (7.9\%), 673.10 (6.9\%), 670.10 (6.8\%), 665.09 (3.6\%), 672.09 (3.4\%), 675.10 (3.2\%), 675.09 (2.4\%), 674.09 (2.4\%), 666.10 (1.3\%). GC: $t_{R}=7.925 \mathrm{~min}$; column: DB-5 $6 \mathrm{~m} \times 0.01 \mathrm{~mm}+1 \mathrm{~m}$ guard column: temp. prog. $50^{\circ} \mathrm{C} / 2 \mathrm{~min} / 22^{\circ} \mathrm{C} / 1$ $\mathrm{min} / 325^{\circ} \mathrm{C} / 10 \mathrm{~min}$; Anal. Calcd for $\mathrm{C}_{33} \mathrm{H}_{29} \mathrm{~N}_{3} \mathrm{O}_{4} \mathrm{PdS}$ (670.09): C, 59.15; H, 4.36; N, 6.27; S, 4.79.; Found: C, 60.54; H, 4.62; N, 6.55; S, 4.86.

(1Z)-6,7,8-trimethoxy-1-(naphthylimino)-1H-isothiochromen4(3H)-one-3-Pd[phen] (5d): Brown solid, Yield: $298 \mathrm{mg}, 53 \%$. Mp: $>300^{\circ} \mathrm{C}$ dec. IR $\left(\mathrm{cm}^{-1}\right)(\mathrm{KBr}), \mathrm{v}(\mathrm{C}=\mathrm{O}, 1672,1542,1422,1340,1148$, 1106, 842, 711, 463.; ${ }^{1} \mathrm{H}$ NMR (DMSO, $300 \mathrm{MHz}$ ): 9.27 (dd, phen, 1 $\mathrm{H},{ }^{1,3} J_{H H}=5$ and $1.5 \mathrm{~Hz}$ ), $9.08\left(\mathrm{dd}\right.$, phen, $1 \mathrm{H},{ }^{1.3} \mathrm{~J}_{H H}=8$ and $\left.1.5 \mathrm{~Hz}\right), 8.48$ (dd, phen, $1 \mathrm{H},{ }^{1,3} \mathrm{~J}_{\mathrm{HH}}=8$ and $1.5 \mathrm{~Hz}$ ), 8.25 (d, naphthyl, $1 \mathrm{H},{ }^{1,3} \mathrm{~J}_{H H}=7.8$ $\mathrm{Hz})$, 7.9-8.1 (m, phen, $4 \mathrm{H}), 8.07$ (d, naphthyl, $\left.1 \mathrm{H},{ }^{1,3} J_{\mathrm{HH}}=7.5 \mathrm{~Hz}\right), 7.95$ (d, naphthyl, $1 \mathrm{H},{ }^{1,3} J_{H H}=8.4 \mathrm{~Hz}$ ), 7.67-7.49 (m, naphthyl, $4 \mathrm{H}$ ), 7.03 (s, C6H1, 1H), 4.14 (s, OMe, 3H), 3.80 (s, OMe, 3H), 3.75 (s, OMe, $3 \mathrm{H})$; LRMS (EI): m/z: $667.06\left[\left(\mathrm{M}^{+}+1\right),(100.0 \%)\right], 665.06(99.7 \%)$, 664.06 (93.1\%), 669.06 (47.1\%), 666.06 (40.9\%), 663.06 (39.2\%), 668.06 (37.0\%), 665.07 (30.8\%), 670.07 (15.9\%), 667.07 (7.0\%), 666.07 (6.3\%), 669.07 (6.0\%), $661.06(3.6 \%), 671.07$ (3.1\%), $671.06(2.5 \%), 670.06$ (2.4\%), 668.07 (1.4\%), 662.07 (1.3\%).; GC: $t_{R}=7.925 \mathrm{~min}$; column: DB-5 $6 \mathrm{~m} \times 0.01 \mathrm{~mm}+1 \mathrm{~m}$ guard column: temp. prog. $50^{\circ} \mathrm{C} / 2 \mathrm{~min} / 22^{\circ} \mathrm{C} / 1$ $\mathrm{min} / 325^{\circ} \mathrm{C} / 10 \mathrm{~min}$; Anal. Calcd for $\mathrm{C}_{33} \mathrm{H}_{25} \mathrm{BrN}_{3} \mathrm{O}_{4} \mathrm{PdS}$ (666.05); C, 59.51; H, 3.78; N, 6.31; S, 4.81.; Found C, 46.89; H, 4.02; N, 4.88; S, 5.05.

\section{Cell culture}

B16 and Vero cells were maintained in an atmosphere of 5\% (v/v) $\mathrm{CO}_{2}$ at $37^{\circ} \mathrm{C}$. $\mathrm{IC}_{50}$ values were obtained using published methodologies. Briefly, $5 \times 10^{3}$ cells/wellwere used to seed 96 well cell culture treated plates (Sigma). Compounds were dissolved at $5 \mathrm{mg} \mathrm{ml}-1$ in sterile DMSO, and further diluted with the appropriate complete cell culture medium. After $72 \mathrm{~h}$, cell viability was assessed using MTT(Sigma), also following published protocols [20,72-74].

\section{Growth inhibitory activity against the human K562 cell line}

K562 human chronic myeloid leukemia cells were maintained in RPM1 1640 medium supplemented with $10 \%$ fetal calf serum and 2 $\mathrm{mM}$ glutamine at $37^{\circ} \mathrm{C}$ in a humidified atmosphere containing $5 \%$ $\mathrm{CO}_{2}$, and were incubated with a specified dose of test agent for $1 \mathrm{~h}$ at $37^{\circ} \mathrm{C}$ in the dark. The incubation was terminated by centrifugation $(5$ min, $300 \mathrm{~g}$ ), and the cells were washed once with drug-free medium. Following the appropriate drug treatment, the cells were transferred to 96-well microtitre plates. Plates were then kept in the dark at $37^{\circ} \mathrm{C}$ in a humidified atmosphere containing $5 \% \mathrm{CO}_{2}$. The assay is based in the ability of viable cells to reduce a yellow soluble tetrazolium salt, 3-(4,5 dimethylthiazol-2-yl)-2,5- diphenyl-2H-tetrazolium bromide (MTT, Sigma Chemical Co.) to an insoluble purple formazan precipitate. The optical density was then read at a wavelength of $550 \mathrm{~nm}$ on a plate reader, and a doseresponse curve was constructed. For each curve, an $\mathrm{IC}_{50}$ value was read as the dose required reducing the final optical density to $50 \%$ of the control value.

\section{Results and Discussion}

In our present work, we describe the synthesis of several palladacycles in the form of TMEDA, bipyridyl and phenanthroline complexes, as well as the screening of these drugs for antitumor activity, depending on the cyclopalladated fine structure, different antitumor properties were observed involving inhibition of the respiratory activity.

Palladium Complexes 3a-d, 4a-d and 5a-d were tested for in vitro anticancer activity against a K562 human leukaemic cell line via a medium throughput screen. For comparison, a number of palladacycles $3 \mathrm{a}-\mathrm{d}, 4 \mathrm{a}-\mathrm{d}$ and $5 \mathrm{a}-\mathrm{d}$ are presented in Table 1 . However, complexes 3a-d, $4 \mathrm{a}-\mathrm{d}$ and $5 \mathrm{a}-\mathrm{d}$ display good in vitro activity, with an $\mathrm{IC}_{50}$ of range (3.02-4.3 $\left.\mu \mathrm{M}\right)$. Having established palladium complexes (3-5)a-d as a "hit" from this primary screen, we have evaluated it in other immortal cell lines namely B16 (Murine Melanoma) and Vero (African Green Monkey Kidney Epithelia) [52-54]. Preliminary data show 3a-d, 4a-d and 5a-d to have submicromolar activity (Figures 1 and 2). Furthermore, some related organo palladium complex has been tested for cathepsin B inhibitory activity [55] and registered an IC50 value of $2.98 \mu \mathrm{M}$, which was in the same range as that of the presented palladium complexes (3-5)a-d (Figure 3).

\begin{tabular}{|c|c|c|c|}
\hline Compound & $\mathbf{N}-\mathbf{N}$ & $\mathbf{E}$ & $\mathbf{I C}_{\mathbf{5 0}} / \mathbf{\mu M}^{\mathbf{a}}$ \\
\hline 3a & TMEDA & & $4.33 \pm 0.05$ \\
\hline 3b & bpy & & $4.34 \pm 0.05$ \\
\hline 3c & dmbpy & & $4.35 \pm 0.05$ \\
\hline 3d & phen & & $4.36 \pm 0.05$ \\
\hline 4a & TMEDA & $\mathbf{O}$ & $3.02 \pm 0.04$ \\
\hline 4b & bpy & $\mathbf{O}$ & $3.03 \pm 0.04$ \\
\hline 4c & dmbpy & $\mathbf{O}$ & $3.05 \pm 0.04$ \\
\hline 4d & phen & $\mathbf{O}$ & $3.14 \pm 0.04$ \\
\hline 5a & TMEDA & $\mathbf{S}$ & $3.014 \pm 0.04$ \\
\hline 5b & bpy & $\mathbf{S}$ & $3.022 \pm 0.04$ \\
\hline 5c & dmbpy & $\mathbf{S}$ & $3.012 \pm 0.06$ \\
\hline 5d & phen & $\mathbf{S}$ & $3.027 \pm 0.05$ \\
\hline
\end{tabular}

aMTT assay from DMSO stock solution on human leukaemic K562 cells. (1h exposure)

Table 1: In vitro activity of palladacycles against a K562 cell line.

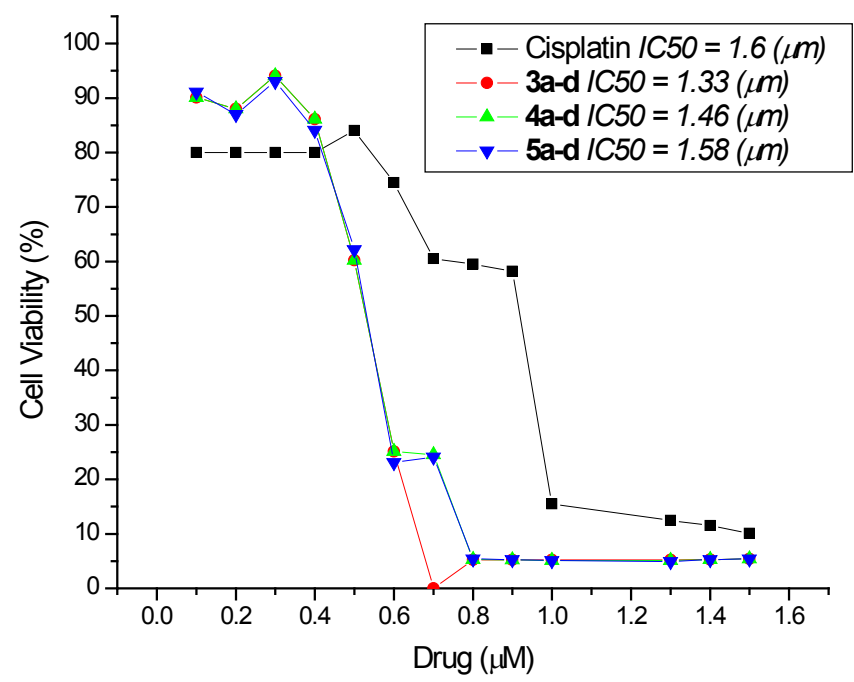

Figure 1: Toxicity of palladacycles 3a-d and cisplatin against Vero cell lines. 


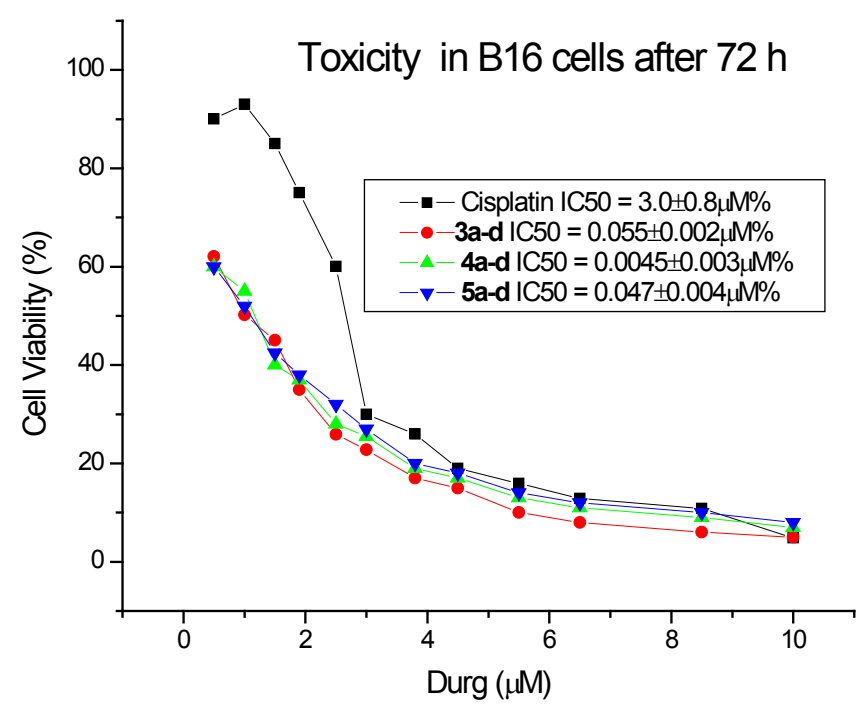

Figure 2: Toxicity of palladacycles 3a-d and cisplatin against B16 cell lines.

Palladacycles 3a-d, 4a-d and 5a-d

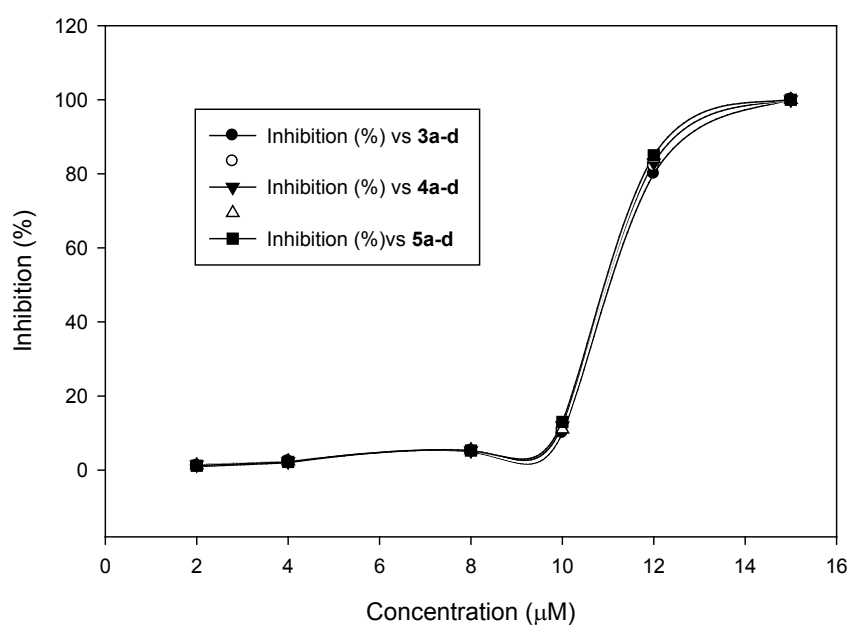

Figure 3: Inhibitory action of Palladacycles (3-5)a-d towards (human liver) cathepsin B.

\section{Synthesis of cis-o-formylaryl palladium complexes $[\mathrm{Pd}(\mathrm{R})$ $\operatorname{Br}\left(\mathrm{L}_{2}\right)$ ] 2a-d; ( $\mathrm{R}=6$-formyl-2,3,4-trimethoxyphenyl}

Reactions of 2-bromo-3,4,5-trimethoxybenzaldehyde 1 with $\left[\mathrm{Pd}_{2}(\mathrm{dba})_{3}\right] . \mathrm{dba}$ ("Pd( $\left.\mathrm{dba}\right)_{2}$ "; $\mathrm{dba}=$ dibenzylideneacetone) the presence of a stoichiometric amount of nitrogen donor ligands, such as $N, N, N$ ', $N$ '-tetramethyl-ethane-1,2-diamine (TMEDA), 2,2'-bipyridine (bpy) 4,4'-dimethyl-2,2'-bipyridine (dmbpy) and 1,10-phenanthroline (Phen) with equimolar ratio in degassed acetone under nitrogen. The resulting mixture was stirred at $0^{\circ} \mathrm{C}$ for $30 \mathrm{~min}$ and at room temperature for $3 \mathrm{hrs}$ to give mononuclear $\sigma$-aryl palladium (II) complexes $2 \mathrm{a}-\mathrm{d}$ in good yields 48-65\%, as outlined in Scheme 1.

It is better to present a generalized picture of mechanistic aspects of this processes begin with the oxidative addition of the organic halide to a $\operatorname{Pd}(0)$ substrate. These reaction seem to take place through a $S_{N}{ }^{2}$ mechanism which is consistent with other group [56-58], and the resulting cis-aryl Pd(II) complexes afforded as described in Scheme 2.
Another piece of evidence to support our configuration and structure determination of the resulting cis- aryl Palladium(II) complexes (3a-d) was presented by the reactions of (aryl) mercury, and aryl mercury bromide with a variety of nitrogen ligands have been studied [59]. The presence of the electron-withdrawing heteroatoms results in these mercurials being stronger acceptors than the corresponding phenylmercury compounds. The most common routes to organomercury compounds involve the direct reaction of mercury with an alkyl bromide, to form the mercury analog of a Grignard Reagent (GR). The subsequent reaction of $\mathrm{RHgBr}$ with potassium cyanide yields the appropriate dialkyl mercury derivative. In order to obtain insight into the pathway of the reaction, we have prepared, these palladacycles (3a-d) [60-64] via a method similar to the one described recently by the reaction of prepared $\left[\mathrm{HgR}_{2}\right]\left(\mathrm{R}=\mathrm{C}_{6} \mathrm{H}(\mathrm{CHO})-6,(\mathrm{OMe})_{3}-2,3,4\right.$ with $\mathrm{Q}_{2}\left[\mathrm{Pd}_{2} \mathrm{Br}_{6}\right]\left[\mathrm{Q}=\left(\mathrm{PhCH}_{2}\right) \mathrm{Ph}_{3} \mathrm{P}\right]$ in acetone results in the precipitation of $\mathrm{Q}_{2}\left[\mathrm{Pd}_{2} \mathrm{R}_{2} \mathrm{Br}_{2}(\mu-\mathrm{Br})_{2}\right]$, which is easily separated from the byproduct $\mathrm{RHgBr}$. reacts with TMEDA, 2,2'-bipyridine or 4,4'-dimethyl-2,2'bipyridine or 1,10-phenanthroline or $\mathrm{PPh}_{3}$ to give [PdRBr(TMEDA)] (3a) or [PdRBr(bpy)] (3b) or [PdRBr(dmbpy)] (3c) or [PdRBr(phen)] (3d) respectively, which are difficult to separate from the byproduct $\mathrm{QBr}$; however, a better method to access these compounds free of impurities starts from $\mathrm{K}_{2}\left[\mathrm{PdBr}_{4}\right]$. To allow both reagents to be in solution, we reacted an aqueous solution of $\mathrm{K}_{2}\left[\mathrm{PdBr}_{4}\right]$ with an acetone solution of $\left[\mathrm{HgR}_{2}\right]$. To our surprise, the reaction occurs without precipitation of any of the reaction products, and if acetone is removed and more water added, the byproduct $\mathrm{RHgBr}$ precipitates quantitatively leaving a yellow aqueous solution of some water-soluble arylpalladium(II) complexes. The dichloromethane solutions of 2,2'-bipyridine (bpy) or 4,4'-dimethyl-2,2'-bipyridine (dmbpy) or 1,10-phenanthroline (phen) added and extraction of the water solution with more dichloromethane added, allow the isolation of complexes $3 \mathrm{~b}$-d in moderate yields (48, $51,53) \%$, respectively. All of these compounds show in their IR spectra a strong band at ca. $1630-1660 \mathrm{~cm}^{-1}$ assignable to $v(\mathrm{CO})$ of the formyl gzroup. This frequency is similar to that observed in $\left[\mathrm{HgR}_{2}\right], \mathrm{HgRBr}$, or 2-bromo-3,4,5-trimethoxybenzaldehyde (1), indicating that there is no coordination of the formyl group to the metal atom.

\section{Reaction with bulky 1-naphthyl isocyanate and isothiocyanate}

Synthesis of cis-o-formylaryl palladium complexes 3a-d: As part of a systematic investigation to discover new organometallic approach, thus the insertion of 1- naphthylisocyanate $(-\mathrm{N}=\mathrm{C}=\mathrm{O})$ and 1-naphthylisothiocyanate $(-\mathrm{N}=\mathrm{C}=\mathrm{S})$ into the $\mathrm{Pd}-\mathrm{C}$ bond, resulting in the formation of imidoyl palladium complexes, constitutes a key step in the palladium-catalyzed of organic substrates in laboratory synthesis and also in industrial processes. The palladacycles $3 \mathrm{a}-\mathrm{d}$ was examined their reactivity towards naphthyl isocyanate in different molars in refluxing toluene afforded the corresponding spiro metalo-complexes of cis-arylpalladium complexes $4 \mathrm{a}-\mathrm{d}$ and cis-arylpalladium complexes $5 \mathrm{a}-\mathrm{d}$ in good yields. as described in Scheme 3. This is probably due to the result of the interchange between nitrogen donor of ligand and the bulky naphthyl isocyanate, which is a very well-unknown process.

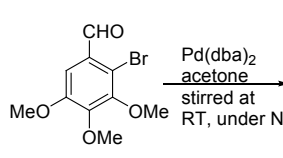

(1)

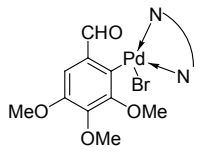

(3a-d)

a) $\mathrm{N}-\mathrm{N}=$ TMEDA

b) $\mathrm{N}-\mathrm{N}=$ bpy

c) $\mathrm{N}-\mathrm{N}=$ dmbpy
d) $\mathrm{N}-\mathrm{N}=$ phen

Scheme 1

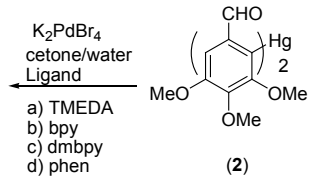

(2) 
(1)

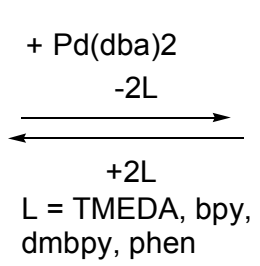

Scheme 2: $S_{N}{ }^{2}$ mechanism of oxidative addition of aryl bromides with $\mathrm{Pd}(0)$ compounds.

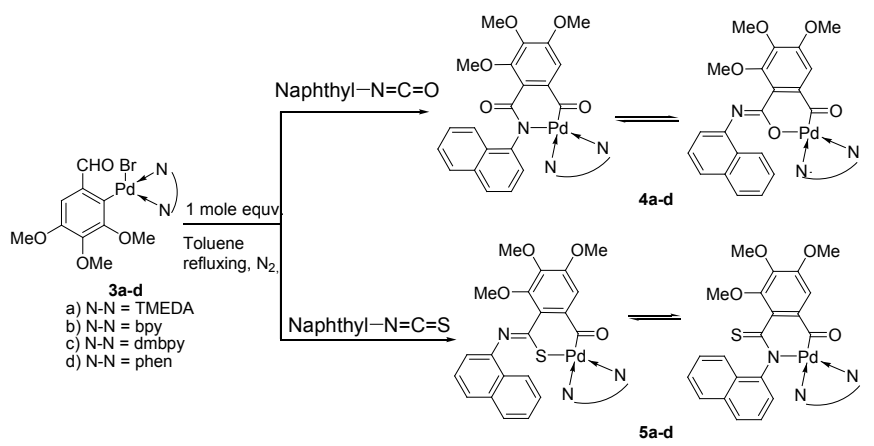

Scheme 3

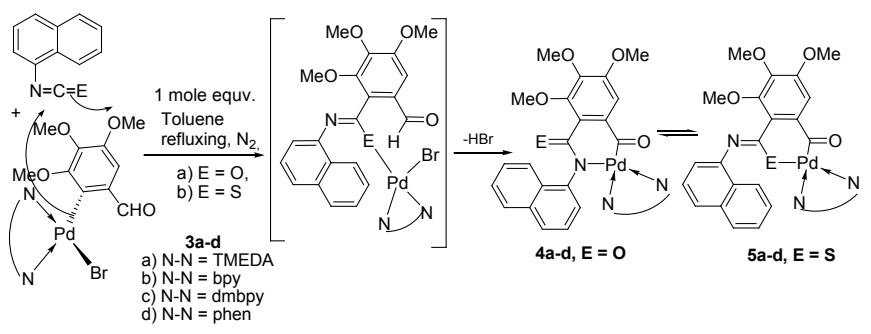

Scheme 4: Schematic representation the synthesis of palladacycles (4a-d) and (5a-d).

One might believe that palladium complexes as intermediates for the formation of complex $4 \mathrm{a}-\mathrm{d}$ and/or $5 \mathrm{a}-\mathrm{d}$. This suggested that the presence of naphthylisocyanate or naphthylisothiocycanate as ligands, could be responsible for the interchange of the ligands and existence of complexes $4 \mathrm{a}-\mathrm{d}$ or $5 \mathrm{a}-\mathrm{d}$ in solution derived from two cis form.

It is better to present a generalized picture of mechanistic aspects of palladacycles with the reactivity towards 1-naphthylisocyanate and 1-naphthylisothiocyanate as models, these reactions of palladium complexes with isocyanates (NCO) and isothiocyanates (RNCS) have been investigated $[65,66]$. The reaction of new cis- $[\mathrm{Pd}\{\mathrm{C} 6 \mathrm{H}(\mathrm{CHO})-$ $\left.\left.\mathrm{OMe}_{3}-3,4,5\right\} \mathrm{Br}(\mathrm{N}-\mathrm{N})\right]$ (3a-d), while (N-N =TMEDA (3a), bpy (3b), dmbpy (3c); phen, (3d)) with RNCE (E=O, S) yields the novel compounds (4a-d) $(\mathrm{E}=\mathrm{O}$ and $\mathrm{R}=$ Naphthyl and $(5 \mathrm{a}-\mathrm{d}), \mathrm{E}=\mathrm{S}$ and $\mathrm{R}=$ Naphthyl); the formation of these complexes results from an addition reaction followed by the migration of a proton from the aldehyde group in the aryl fragment to the bromide in the (L2) $\mathrm{PdBr}$ moieties.

These resulting compounds having 3,4,5-trimethoxyphenyl group similar to analogues of cactus alkaloid, mescaline [beta- $(3,4,5$ trimethoxyphenyl)-arylmethylamine], that were used for induced changes of brain-cortex ribosomes [67]. In complexes 4a-d show in their IR spectra, a strong band at $1665 \mathrm{~cm}^{-1}$ assignable to $v(\mathrm{CO})$ group. This frequency is similar to that observed in iso-indenone, indicating that there is coordination of the formyl group to the isocyanate inserted. A piece of evidence to support our assumption that the reasons of inhibition the insertion of naphthyl isocyanate into bulky substrates, this caused by the steric hindrance of bulky reactants. The ${ }^{1} \mathrm{H}$ NMR spectrum at room temperature indicates that formation of the complexes seems to be favored by the potentially great steric hindrance and their ligands were in a square planar disposition. In this case, such steric hindrance should monitored by UV during the reaction process. All the reactions of aryl palladium complexes with 1-naphthylisocyanate (NCO) and 1-naphthylisothiocyanate (NCS) were investigated, and some of these results were consistent with the results reported recently [62-64,68]. The band assignable to $v(\operatorname{aryl})$, $v$ (bpy), $v$ (dmbpy) and $v$ (phen) in the IR spectra of the palladacycles are observed within the range $1515-1731 \mathrm{~cm}^{-1}$ and two bands at 1716 and $1615 \mathrm{~cm}^{-1}$; one of them may be due to the $\mathrm{v}(\mathrm{C}=\mathrm{C})$, and the other remaining band may be assignable to the $v(\mathrm{C}=\mathrm{N})$ mode, corresponding to the ligands coordinated to the palladium atom. Complexes 3a$\mathrm{d}, 4 \mathrm{a}-\mathrm{d}$ and $5 \mathrm{a}-\mathrm{d}$ were tested for in vitro anticancer activity against a K562 human leukaemic cell line via a medium throughput screen. For comparison, a number of palladacycles $3 \mathrm{a}-\mathrm{d}, 4 \mathrm{a}-\mathrm{d}$ and $5 \mathrm{a}-\mathrm{d}$ were synthesized and tested (Table 1). However, complexes of palladacycles $4 \mathrm{a}-\mathrm{d}$ and $5 \mathrm{a}-\mathrm{d}$ displays good in vitro activity, with an $\mathrm{IC}_{50}$ of $4.3 \mu \mathrm{M}$. Having established $5 \mathrm{a}-\mathrm{d}$ as a "hit" from this primary screen, we have evaluated it in other immortal cell lines namely B16 (Murine Melanoma) and Vero (African Green Monkey Kidney Epithelia) [52-54]. Preliminary data show 3a-d to have submicromolar activity (Figures 1-3). Furthermore, similar palladacycles has been tested for cathepsin B inhibitory activity and registered an IC50 value of 2.98$3.20 \mu \mathrm{M}$, which is in the same range as that of a dimeric dppf bridged C,N-palladacycle (dppf=1,1'-bis(diphenylphosphine)-ferrocene) [55].

\section{Conclusion}

Novel Palladacycles 3-5 give a good result of inhibitory activity against cathepsin $\mathrm{B}$ and leukimia cells in vitro over a wide concentration range. Palladacycles $3 \mathrm{a}-\mathrm{d}$ is cytotoxic and inhibits cathepsin $\mathrm{B}$ with $\mathrm{IC}_{50}$ values in the low $\mu \mathrm{M}$ range [52-54]. This study are aiming to address some complexes can be used as biological probes for proteins and biomolecules, e.g. cysteine, selenocysteine proteases [73-75]. All these exciting aspects of palladacycle chemistry will be divulged in due course.

\section{Acknowledgements}

The authors are grateful to Cancer Research Technology and Robin Leach, MDS Pharma Services, are thanked for helpful discussions. This paper is dedicated to Professor José Vicente Soler for his contributions to Organometallic Chemistry and exploiting palladacycles Chemistry.

\section{References}

1. Navarro-Ranninger C, Lopez-Solera I, Perez JM, Masaguer JR, Alonso C (1993) Appl Organomet Chem 7: 57-61

2. Dupont J, Consorti CS, Spencer J (2005) The potential of palladacycles: more than just precatalysts. Chem Rev 105: 2527-2571.

3. Dupont J, Pfeffer M, Spencer J (2001) Eur J Inorg Chem 1917-1927.

4. Dupont J, Pfeffer M, Ryabov (2008) in Palladacycles, ed. Wiley-VCH, Weinheim ch 13: 307-339.

5. Higgins JD 3rd, Neely L, Fricker S (1993) Synthesis and cytotoxicity of some cyclometallated palladium complexes. J Inorg Biochem 49: 149-156.

6. Navarro-Ranninger C, Lopez-Solera I, Gonzales VM, Perez JM, AlvarezValde's A, et al. (1996) Inorg Chem 35: 5181.

7. Navarro-Ranninger C, López-Solera I, Pérez JM, Rodríguez J, García-Ruano $\mathrm{JL}$, et al. (1993) Analysis of two cycloplatinated compounds derived from N-(4methoxyphenyl)-alpha-benzoylbenzylidenamine. Comparison of the activity of these compounds with other isostructural cyclopalladated compounds. J Med Chem 36: 3795-3801. 
Citation: Hamad Elgazwy ASS, Shehata MR, Zaki MY, Solima DHS, Elbakkry MM (2013) Synthesis of Novel Palladacycles Inhibitors of the Cathepsin B Activity and Antitumoral Agents. Med chem 3: 254-261. doi:10.4172/2161-0444.1000148

8. Quiroga AG, Pérez JM, López-Solera I, Masaguer JR, Luque A, et al. (1998) Novel tetranuclear orthometalated complexes of $\mathrm{Pd}(\mathrm{II})$ and $\mathrm{Pt}(\mathrm{II})$ derived from p-isopropylbenzaldehyde thiosemicarbazone with cytotoxic activity in cis-DDP resistant tumor cell lines. Interaction of these complexes with DNA. J Med Chem 41: 1399-1408.

9. Perez AG, Quiroga AG, Montero El, Alonso C (1999) Navarro-Ranninger CJ. Inorg Biochem 73: 235.

10. Rodrigues EG, Silva LS, Fausto DM, Hayashi MS, Dreher S, et al. (2003) Cyclopalladated compounds as chemotherapeutic agents: antitumor activity against a murine melanoma cell line. Int J Cancer 107: 498-504

11. Bhandarkar SS, Bromberg J, Carrillo C, Selvakumar P, Sharma RK, et al. (2008) Tris (dibenzylideneacetone) dipalladium, a N-myristoyltransferase-1 inhibitor, is effective against melanoma growth in vitro and in vivo. Clin Cancer Res 14: 5743-5748.

12. lacobuzio-Donahue CA, Shuja S, Cai J, Peng P, Murnane MJ (1997) Elevations in cathepsin B protein content and enzyme activity occur independently of glycosylation during colorectal tumor progression. J Biol Chem 272: 29190 29199.

13. Sloane BF, Rozhin J, Johnson K, Taylor H, Crissman JD, et al. (1986) Cathepsin B: association with plasma membrane in metastatic tumors. Proc Natl Acad Sci U S A 83: 2483-2487.

14. Almeida PC, Nantes IL, Rizzi CCA, Judice WAS, Chagas JR, et al. (1999) Biol Chem 274: 30433

15. Almeida PC, Nantes IL, Chagas JR, Rizzi CC, Faljoni-Alario A, et al. (2001) Cathepsin $B$ activity regulation. Heparin-like glycosaminogylcans protect human cathepsin B from alkaline $\mathrm{pH}$-induced inactivation. J Biol Chem 276: 944-951.

16. Heck RF (1985) Palladium Reagents in Organic Synthesis; Academic Press: New York.

17. Bincoletto C, Tersariol IL, Oliveira CR, Dreher S, Fausto DM, et al. (2005) Chiral cyclopalladated complexes derived from $\mathrm{N}, \mathrm{N}$-dimethyl-1-phenethylamine with bridging bis(diphenylphosphine)ferrocene ligand as inhibitors of the cathepsin $B$ activity and as antitumoral agents. Bioorg Med Chem 13: 3047-3055.

18. Caires ACF, Almeida ET, Mauro AE, Hemerly JP, Valentini SR (1999) Quimica Nova 22: 329-334.

19. Spencer J, Sharratt DP, Dupont J, Monteiro AL, Reis VI, et al. (2005) Organometallics 24: 5665-5672.

20. Spencer J, Chowdhry BZ, Mallet Al, Rathnam RP, Adatia T, et al. (2008) Tetrahedron 64: 6082-6089.

21. Wunberg T, Hendrix M, Hillisch A, Lobell M, Meier H, et al. (2006) Drug Discovery Today 11: 175-180.

22. Proudfoot JR (2002) Drugs, leads, and drug-likeness: An analysis of some recently launched drugs. Bioorg Med Chem Lett 12: 1647-1650.

23. Higgins JD 3rd, Neely L, Fricker S (1993) Synthesis and cytotoxicity of some cyclometallated palladium complexes. J Inorg Biochem 49: 149-156.

24. Navarro-Ranninger C, López-Solera I, Pérez JM, Rodríguez J, García-Ruano $\mathrm{JL}$, et al. (1993) Analysis of two cycloplatinated compounds derived from N-(4methoxyphenyl)-alpha-benzoylbenzylidenamine. Comparison of the activity of these compounds with other isostructural cyclopalladated compounds. J Med Chem 36: 3795-3801.

25. Hartwig JF (1998) Chem Int Ed 37: 2047.

26. Elgazwy ASSH (2003) Tetrahedron 59: 7445-7463.

27. Tsuji J (1995) Palladium Reagents and Catalysis. Wiley: Chich-ester, UK.

28. Wolfe JP, Wagaw S, Marcoux JF, Buchwald SL (1998) Acc Chem Res 31: 805.

29. Shibasaki M, Vogl EM (1999) J Organomet Chem 576: 1.

30. Loiseleur O, Hayashi M, Keenan M, Schmees N, Pfaltz A (1999) J Organomet Chem 576: 16.

31. Herrmann WA, Bohm VPW, Reisinger CP (1999) J Organomet Chem 576: 23.

32. Cacchi S (1999) J Organomet Chem 576: 42.

33. Larock RC (1999) J Organomet Chem 576: 111.

34. Suzuki J (1999) Organomet Chem 576: 147.

35. Dupont J, Pfeffer M, Spencer J ((2001)) Eur J Inorg Chem 1917
36. Cope AC, Friedrich EC (1968) J Am Chem Soc 90: 909.

37. Alper HJ (1973) Organomet Chem 61: C62.

38. Dehand J, Mauro A, Ossor H, Pfeffer M, Santos RHD, et al. (1983) J Organomet Chem 250: 537.

39. McPherson HM, Wardell JL (1983) Inorg Chim Acta 75: 37.

40. Elgazwy ASSH (2007) Applied Organometallic Chemistry 21: 1041-1053.

41. Elgazwy ASSH (2008) Monatshefte für Chemie 139: 1285-1297.

42. Dupont J, Pfeffer M, Wiley-V CH, RyabovA (2008) in Palladacycles. Weinheim 13: $307-339$.

43. Elgazwy ASSH (2009) Polyhedron 28: 349-359.

44. Elgazwy ASSH (2009) Polyhedron 28: 3667-3674.

45. Ziegler FE, Chliwner 1, Fowler KW, Kanfer SJ, Kuo SJ, et al. (1980) J Am Chem SOC 102: 790

46. Tomioka K, Ishiguro T, Mizuguchi H, Komeshima N, Koga K, et al. (1991) Absolute structure-cytotoxic activity relationships of steganacin congeners and analogues. J Med Chem 34: 54-57.

47. Chan JH, Roth B (1991) 2,4-Diamino-5-benzylpyrimidines as antibacterial agents. $\quad 14 . \quad 2,3-D i h y d r o-1-(2,4-d i a m i n o-5-p y r i m i d y l)-1 \mathrm{H}$-indenes as conformationally restricted analogues of trimethoprim. J Med Chem 34: 550555.

48. Ringel I, Jaffe D, Alerhand S, Boye O, Muzaffar A, et al. (1991) Fluorinated colchicinoids: antitubulin and cytotoxic properties. J Med Chem 34: 3334-3338.

49. Spnth E (1919) Monatsh 40: 129.

50. Tsao MU (1951) J Am Chem Soc 73: 5495.

51. Reti L (1953) In: Manske \& Holmes (Ed.), The Alkaloids, Vol. III 22: 313.

52. Spencer J, Mendham AP, Kotha AK, Richardson SC, Hillard EA, et al. (2009) Structural and biological investigation of ferrocene-substituted 3-methylidene1,3-dihydro-2H-indol-2-ones. Dalton Trans 918-921.

53. Richardson SC, Winistorfer SC, Poupon V, Luzio JP, Piper RC (2004) Mammalian late vacuole protein sorting orthologues participate in early endosomal fusion and interact with the cytoskeleton. Mol Biol Cell 15: 11971210.

54. Richardson S, Ferruti P, Duncan R (1999) Poly(amidoamine)s as potential endosomolytic polymers: Evaluation in vitro and body distribution in normal and tumour-bearing animals. J Drug Target 6: 391-404.

55. Commercial IC50 determinations were performed by MDS Pharma Services (http://www.mdsps.com): assay 112250, CTSB (Cathepsin B). Brief details: substrate $20 \mathrm{mM}$ Boc-Leu-Arg-Arg-AMC, 1\% DMSO vehicle by spectrofluorimetric quantitation of AMC.

56. Tsao MU, Van Dyke E (1955) J Am Chem Soc 77: 6693.

57. Grove DM, van Koten G, Louwen JN, Noltes JG, Speck AL, et al. (1982) J Am Chem Soc 104: 6609.

58. Rietveld MHP, DM Grove, van Koten G (1997) New J Chem 21: 751.

59. Tu ek-Bo L, D'Alpaos M (1998) Polyhedron 17: 1481-1493.

60. Hirai Y, Igashira-Kamiyama A, Kawamoto T, Konno T (2007) Chem Lett 36 434

61. Gilman H, Barnett MM (1936) des Travaux. C des Pays-Bas 55: 563-566.

62. VicenteJ, Abad JA, Stiakaki MA, Jones PG (1991) J Chem SOC Chem Commun 137.

63. Vicente J, Abad JA, Jones PGn (1992) Organometallics 11: 3612

64. Vicente JJ, Abad A Lahoz FJ, Plou FJ (1990) J Chem Soc Dalton Trans 1459.

65. Gareth R Owen, Andrew JP (2009) White and Ramon Vilar Organometallics 28: 5783-5793.

66. Gareth R Owen, Ramón Vilar, Andrew JP White, David J Williams (2003) Organometallics 22: 4511-4521.

67. Gilman H, Barnett MM (1936) Recueil des Travaux Chimiques des Pays-Bas 55: 563

68. Shimizu D, Takeda N, Tokitoh N (2007) J Organomet Chem 692: 2716. 
Citation: Hamad Elgazwy ASS, Shehata MR, Zaki MY, Solima DHS, Elbakkry MM (2013) Synthesis of Novel Palladacycles Inhibitors of the Cathepsin B Activity and Antitumoral Agents. Med chem 3: 254-261. doi:10.4172/2161-0444.1000148

69. Takahashi Y, Ts Ito, Sakai S, Ishii Y (1970) Journal of the Chemical Society D: Chemical Communications 1065.

70. Paquette LA (1996) Encyclopedia of Reagents for Organic Synthesis. J Wiley and Sons, Sussex, England, UK.

71. Pierpont CG, Mazza MC (1974) Inorg Chem 13: 1891.

72. Bincoletto C, Tersariol IL, Oliveira CR, Dreher S, Fausto DM, et al. (2005) Chiral cyclopalladated complexes derived from $\mathrm{N}, \mathrm{N}$-dimethyl-1-phenethylamine with bridging bis(diphenylphosphine)ferrocene ligand as inhibitors of the cathepsin $B$ activity and as antitumoral agents. Bioorg Med Chem 13: 3047-3055.
73. Spencer J, Sharratt DP, Dupont J, Monteiro AL, Reis VI, et al. (2005) Organometallics 24: 5665-5672.

74. Casini A, Gabbiani C, Sorrentino F, Rigobello MP, Bindoli A, et al. (2008) Emerging protein targets for anticancer metallodrugs: inhibition of thioredoxin reductase and cathepsin B by antitumor ruthenium(II)-arene compounds. J Med Chem 51: 6773-6781.

75. Elgazwy AS, Ismail NS, Atta-Allah SR, Sarg MT, Soliman DH, et al. (2012) Palladacycles as antimicrobial agents. Curr Med Chem 19: 3967-3981. 